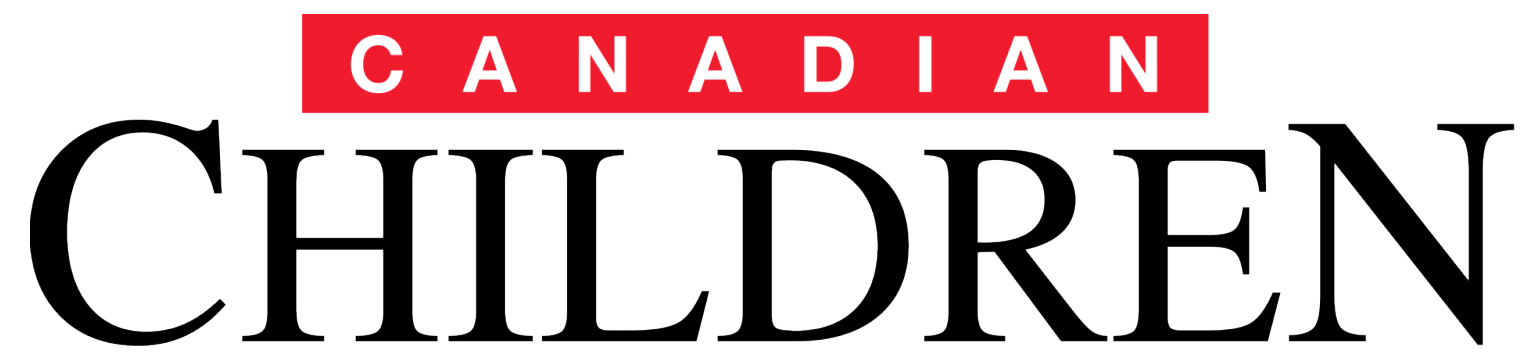

JOURNAL OF THE CANADIAN ASSOCIATION FOR YOUNG CHILDREN

Winter 2015/Hiver 2015

Vol. 40 No. 1

\title{
Beyond Professionalism: \\ Interrogating the Idea and the Ideals
}

By Randa Khattar and Karyn Callaghan

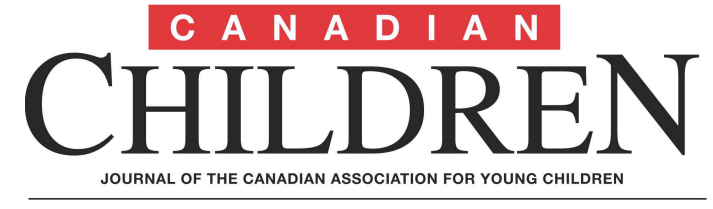

Winter 2015/Hiver 2015

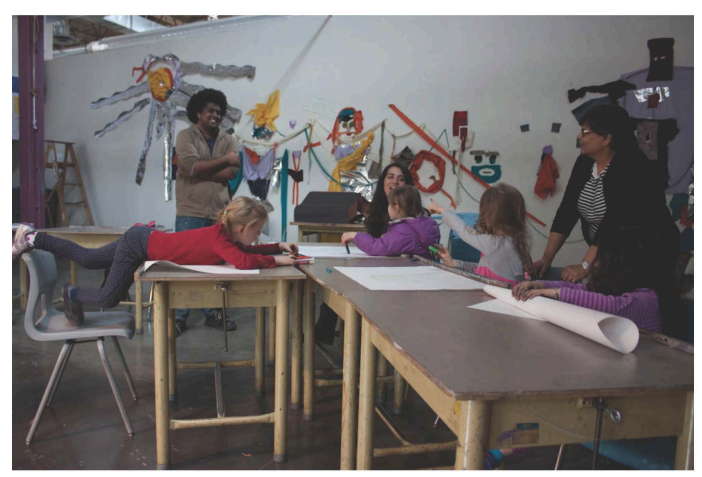

Editors:

Dr. Laurie Kocher, Douglas College, Coquitlam, British Columbia Dr. Veronica Pacini-Ketchabaw, University of Victoria, Victoria, British Columbia

Guest Editors, Special Issue: Professionalism in ECEC Dr. Rachel Langford, Dr. Jane Hewes, Sonya Hooper, and Monica Lysack

Publications Chairperson:

Dr. Iris Berger,

University of British Columbia,

Vancouver, British Columbia

Cover Photo:

Dr. Sylvia Kind

(c) 1996: The Canadian Association for Young Children ISSN: 0833-7519

Author Guidelines: visit www.cayc.ca

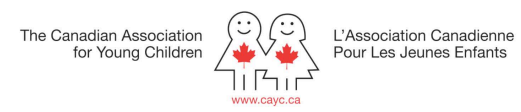

The Canadian Association
for Young Children

Published with support from the Social Sciences and Humanities Research Council of Canada

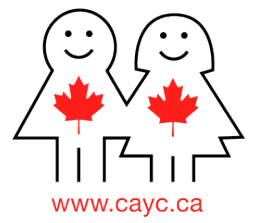




\title{
Canadian Children
}

\section{JOURNAL OF THE CANADIAN ASSOCIATION FOR YOUNG CHILDREN}

Volume 40 Number 12015 [page 5 to 19]

www.cayc.ca

\section{Professionalism: Interrogating the Idea and Ideals}

\section{by Randa Khattar and Karyn Callaghan}

\begin{abstract}
Authors' Bios
Randa Khattar researches in the areas of social justice, attentiveness practices, and children's rights. She teaches in the bachelor of early childhood studies program at Charles Sturt University in Burlington, Ontario, and Australia. Email: rkhattar@csu.edu.au

Karyn Callaghan is the program coordinator and lecturer in the bachelor of early childhood studies program at Charles Sturt University, president of the Ontario Reggio Association, a national director of the Canadian Association for Young Children, and a member of the board of directors for the North American Reggio Emilia Alliance. Karyn has been a consultant to the Ontario Ministry of Education Early Years Division in the past two years, contributing to the development of its new documents. Email: kcallaghan@csu.edu.au
\end{abstract}

\begin{abstract}
Taking up the early childhood tertiary classroom as a microcosm of the field, this paper engages with a series of parallel questions meant to problematize narrow understandings of professionalism and views of the educator regularly circulating in the field. By examining some of the structural and discursive contexts organizing/ruling early childhood educators' lives, the paper offers up a conversation meant to rethink the work of early childhood in intellectually liberating and democratic ways.
\end{abstract}

\section{Considerations of the Conditions of Professionalism}

Peter Moss (2010) offers this provocation to the early childhood education (ECE) field: "Perhaps it is time to move beyond "professionalism"" (p. 17). Moss writes this with an aim to interrogate narrow, and perhaps impoverishing, views of professionalism which may obfuscate more urgent debates about what he terms the broader contexts of democracy, citizenship, diversity, and ecological survival. A conversation is burgeoning in local and international settings that questions narrow views of professionalism. This 
conversation, timely in the Canadian context, provokes us to think beyond technical, instrumental views of the early childhood educator that draw largely on industrial and neoliberal (Dahlberg, Moss, \& Pence, 2007) metaphors for sustenance, and on perspectives that may limit professionalism to conformist sensibilities, abrogating more transformational orientations (MacNaughton, 2003). This conversation coincides with a change in how we view children. Ultimately, children are affected by how their educators view themselves and are viewed. We feel that our views of children should inform our thoughts about what it means to be professional educators. This confluence of discussions is not only generative, but essential.

Competing enactments of professionalism are evident in the values, knowledge, and practices of early childhood educators. As early childhood teacher educators in an Ontario ECE tertiary program, we see the early childhood classroom as a microcosm reflecting this broader conversation on professionalism that is taking place in our field. In this paper, we engage with a series of parallel questions germane to this conversation: Which competing ideas, values, and tools shape understandings of professionalism in early childhood? Which appear to narrow and which expand definitions of professionalism? Which seek to go "beyond professionalism"? These questions problematize issues we experience regularly in the early childhood tertiary classroom, but of course, faculty in ECE programs are also closely connected to ECE professionals in the community, so these questions are not limited to students.

We argue that deploying regular opportunities to grapple with these kinds of questions helps to keep our understandings of professionalism in tension and thus maintain an open stance to listening responsively to new and broadening perspectives. Here, we focus on recent Ontario early childhood policy papers to explore, tease out, and trouble definitions of professionalism, in particular, Early Learning for Every Child Today (Best Start Expert Panel on Early Learning, 2007), known colloquially as the ELECT document, and the recently released How Does Learning Happen? (Ontario Ministry of Education, 2014). Both documents discuss the roles and responsibilities of the early childhood educator in Ontario and may imply conceptions of professionalism that are different from each other. We also draw on an international examination of professionalism in 15 countries to consider possibilities for redefining the contours of professionalism using the vocabulary of competent systems.

\section{Conformist and Transformational Conversations about Professionalism}

Calls abound for more professionalism, more accountability, more knowledge, and more quality in the ECE field. However, Moss's words, "beyond professionalism," invite us to question what is really meant by these calls. Moss and others suggest that certainty, control, and predictability function as mental maps informing how we see, think, feel, and act (Lakoff \& Johnson, 2003), and these maps delineate the dominant 
boundaries of professionalism. MacNaughton (2003) identifies key social, political, and economic tensions that undermine potential transformative change as conformist mindsets and normative discourses. In an ocean of possible conversations we could be having about professionalism in early childhood, these dominant discourses (MacNaughton, 2005) act like undertows, attracting attention to particular articulations of professionalism while marginalizing others. There are benefits from the standpoint of public perception, yet there is a simultaneous playing into the inclination or expectation to position early childhood educators and their field within conformist perspectives ruled by a regulatory gaze (Foucault, 1978; Osgood, 2006). Cannella (1997) critiques the propensity to define professionalism using the language of standards of "goodness" and/or "normalcy":

The discourses and actions associated with professional institutions and practices have generated disciplinary and regulatory powers over teachers (who are mostly women) and children. Standards have been created through which individuals judge and limit themselves, through which they construct a desire to be 'good,' 'normal' or both. (p. 137)

Cannella argues that opportunities exist to interrogate professionalization in ways that trouble the term's historically steeped pedagogic authority, its homogenization of professional knowledge, and its devaluing of non-Western knowledges in pursuit of those that legitimate Western science. In addition, it is possible to imagine conversations that challenge "the claim to professional status [that] rests on a simple bargain: technical competence ... exchanged for technical autonomy, practical knowledge for control over practice" (Labaree, 1992, p. 125). Yet early childhood professionalism is often regulated within contexts that offer up inducements or rewards that externalize feelings of satisfaction and gratification, and thus encourage compliance, reducing intrinsic motivation to interrogate what is at times professionalism's regulatory gaze (Osgood, 2006). One may not be inclined to "bite the hand" that has just given a certificate with a silver bar on it.

Many of our conversations with students and colleagues have focused on "quality" as a central aspect of professionalism. In communities throughout Ontario, initiatives have sprung up in an effort to support "quality." These initiatives often require educators to complete a set number of hours of "professional development" to achieve levels of recognition (such as Affiliated Services for Children and Youth, 2002). Some of these initiatives are characterized by a propensity to focus on views of the educator as becoming or as being made ready for the next stage or level of professional development. Although traditional notions of what constitutes professional development and quality have been soundly critiqued (Dahlberg, Moss, \& Pence, 2007; Penn, 2009), "quality"defined orientations continue to form a mainstay of dominant discourses and require further interrogation.

\section{Canadian Children}




\section{A Microcosm Reflecting Broader Conversations}

We offer up an honours bachelor tertiary ECE classroom as a microcosm of competing conversations and interrogations of professionalism that we think need to take hold of the public imagination and broaden understandings of the roles and responsibilities of early childhood professionals. Our students are part of a group of pedagogues within the ECE field who are engaged in furthering their education. Given the focus of our particular program, which is grounded in poststructural, feminist, critical, and decolonizing approaches, the students are encouraged to problematize and grapple with the seminal and current issues of the field. These conversations are intended to provide students with nuanced opportunities to examine competing articulations of professionalism and to invite them to engage in healthy critique of policy, practice, and “common sense." We would like, as Foucault (1988) puts it, to

show that things are not as self-evident as one believed, to see [that] that which is accepted as self-evident will no longer be accepted as such ... since as soon as one can no longer think as one formerly thought then transformation becomes both very urgent, very difficult and quite possible. (p. 155)

Theoretically grounded discussion must be joined with a critique of practice. A "permanently critical attitude" (Freire, 1974, p. 5) to both "read the world" and to simultaneously grasp that the educator's role to "bring out the fact that there are other readings of the world" at times in opposition to the educator's own (Moss, 2010, p. 15) informs the students' (and our) practice. The task of adopting this attitude is often very difficult, particularly when it questions closely cherished assumptions and certainties. Yet, as hooks (2010) argues, "when we make a commitment to become critical thinkers, we are already making a choice that places us in opposition to any system of education or culture that would have us be passive recipients of ways of knowing" (p. 185).

Required also, we are finding, is a critical disposition based in relationships (Edwards, Gandini, \& Forman, 2012; Fraser, 2011). Relationship, as Malaguzzi (1993) reminds us, is not to be understood "simply as a warm protective backdrop or blanket but as a coming together of elements interacting dynamically toward a common purpose" ( $\mathrm{p}$. 10). Malaguzzi (1994) further challenges us with his advice that

life has to be somewhat agitated and upset, a bit restless, somewhat unknown. As life flows with the thoughts of the children, we need to be open, we need to change our ideas; we need to be comfortable with the restless nature of life. (p. 2)

The practice of interrogating ideas and practices within the context of fostering critical friendships is also essential. As Costa and Kallick (1993) write, 
a critical friend can be defined as a trusted person who asks provocative questions, provides data to be examined through another lens, and offers critiques of a person's work as a friend. A critical friend takes the time to fully understand the context of the work presented and the outcomes that the person or group is working toward. The friend is an advocate for the success of that work. (p. 50)

Within this context of critical collaboration, we have regular opportunities to think deeply with our students (and colleagues) about what it means to consider the multiple competing discourses of professionalism, and, borrowing heavily from Frierian critical pedagogies (1970) and Foucauldian approaches to criticism (1988), to interrogate commonsense assumptions and "truths" afforded to professionalism. Mirroring tensions that are ubiquitous in the field, these are difficult but necessary conversations because they challenge deeply held beliefs and assumptions, and, more importantly, invite an examination of everyday tacit practices that often do not reflect professed views of children or the early childhood educator.

In our teacher education practice, we have found that tensions arise, particularly when students begin to critically reflect on deeply held beliefs about children's growth as measured by developmentalism, and when they reflect on the tacitly held adherences to technical-instrumental views of early childhood educators and ECE and attendant developmentally appropriate and constructivist teaching practices. Students begin to recognize that these beliefs arise from a view of the child who is becoming, who needs to be made ready for the next stage, or whose needs and deficiencies must be fixed so that the child might be "normalized." These approaches, despite benevolent aims, may serve to "reduce the complexities and diversities of learning and knowing" and "simultaneously shut out the inclusion and justice we want to achieve" (Lenz Taguchi, 2010, p. 8). These aspirations may not sit well as those of a critically reflective professional.

As a view of the competent child is reconsidered, a broader view of the educator who is not simply becoming but can meet and learn with and from this child, who can welcome uncertainty and complexity, who can have a voice and influence in their own schools and communities, and who can question the dominant discourse can take hold. It is an approach that makes "visible and possible the potentialities of the child" (Lenz Taguchi, 2010, p. 85) - and, we argue, also of the educator. The view of the competent child questions the primacy of developmentalism that both theoretically and in practice tends to measure how similar or different one child is to others in typically similar contexts (Katz, 1996) or depicts development as "unitary, irrespective of culture, class, gender, or history" (Burman, 1994, p. 185). This view needs to be met by a contemporaneous view of the educator as rich in potential, powerful, competent, connected, and connecting, as a "public intellectual" (Giroux, 1990, p. 361).

\section{Canadian Children}


An accompanying articulation of professionalism as, for example, engaging with society's youngest citizens with rights (e.g., Rinaldi, 2006; United Nations, 1989) positions early childhood educators differently and more expansively from technist, instrumental perspectives. These more expansively envisioned educators are engaged agents of change and advocates participating in a growing conversation that is honed by democratic participation and global citizenship, with concern for a "more than human" world (Abram, 1996).

\section{A Transformation in Ontario Policy Framework}

As two Ontario educators working at the tertiary level, we feel privileged to be witnessing and participating in a powerful change that is slowly bubbling across the early childhood landscape in our province. Our early childhood economic and social contexts resemble many others, both locally and globally. In Ontario as elsewhere, the population of ECE students/professionals is overwhelmingly female, and within this subset, a significant majority may choose to "care" for young children because it is a traditionally female role-what women "naturally" do (Cannella, 1997). A recent survey of 215 beginning ECE students in Ontario identifies "enjoyment of children" as the most common reason for being attracted to the ECE field (Winder \& Corter, 2014, p. 14). While the potential for playing a role in encouraging and supporting social change is significant in this work (Pelo, 2008), few students embrace this as a goal; fewer than onequarter of beginning students surveyed by Winder and Corter (2014) listed "to make a difference" as their reason for entering the field. It would appear that most students ascribe to a conformist view (MacNaughton, 2005) and do not see themselves or their work as political. Given the opportunity and a transformational mindset, however, ECE students and professionals are highly capable of critical reflection interrogating the status quo, and of addressing oppression and unearned privilege as steps leading to transformative practice (MacNaughton, 2003).

One indication of how a profession is viewed is through frameworks and policy documents, which can be seen as reflecting underlying beliefs that are often not stated. While frameworks and documents often reflect the dominant discourse and play a role in validating the status quo, they can play a transformative role. They can establish a context of compliance or invite participation. In Ontario, we are experiencing a transformation. The recently released How Does Learning Happen? establishes its intention clearly:

This resource guide is intended to inspire educators and administrators in early years settings and to ignite critical reflection and discussion.

(Ontario Ministry of Education, 2014, p. 12)

This is an invitation for professionals to participate in meaning making. In contrast to documents that spell out the lists of knowledge and skills early childhood 
educators need to identify (and measure) in children, this document articulates the following view of the child:

We view children as competent, capable of complex thinking, curious, and rich in potential. They grow up in families with diverse social, cultural, and linguistic perspectives. Every child should feel that he or she belongs, is a valuable contributor to his or her surroundings, and deserves the opportunity to succeed. When we recognize children as capable and curious, we are more likely to deliver programs and services that value and build on their strengths and abilities. (Ontario Ministry of Education, 2014, p. 6)

In addition to the articulated view of the child, in itself a signal of a paradigm shift, this document also presents a view of the educator and family as "competent and capable, curious, and rich in experience" (Ontario Ministry of Education, 2014, p. 7). When all partners in learning — child, family, and educator — are recognized as protagonists, the hierarchy is disrupted. Taken together, these views can be seen as an expression of confidence in the professional abilities of the educator. It is a move away from a positivist stance derived from developmentalism. A view is a choice. If taken up, it would need to be made concrete in decisions every day. A view can provide the foundation for critically reflective practice.

The previous Ontario policy document for the early years, Early Learning for Every Child Today (the ELECT document, Best Start Expert Panel on Early Learning, 2007), does not articulate an underlying view of the child or educator, but states that the early childhood educator is expected to use a developmental continuum that stretches from page 24 to page 68 of the document as "a guide that identifies sequences of development as a foundation to implementing early childhood curriculum and pedagogy in a variety of settings" (p. 22). The verb "implementing" may conjure up an image of a technician rather than one who is involved in intellectual, critically reflective, professional work. For each root skill, examples of interactions with educators are provided. For example, in the birth to 24 months grouping, the interaction suggested for skill 3.3 is as follows: "Imitate the infant's vocalizations. Infant: 'Ba, ba!' Adult: 'Ba, ba!'” (p. 27). One must wonder if other professionals are provided with such detailed scripting. In MacNaughton's (2005) opinion, "a technocratic view of teacher decisionmaking dominates a majority of mainstream early childhood literature" (p. 18). The very format of a numbered list of skills and interactions may communicate a sense of certainty regarding the sequence that educators should be monitoring and programming for. A focus on lists of skills may have the impact of diminishing complexity and may push educators into the role of technicians who know (or must know) what they are looking for, record it, and then plan accordingly to get the child to the next skill. Marshall McLuhan's (1994) statement that the medium is the message, that we shape our tools and 
thereafter our tools shape us, merits serious consideration in this context. Perhaps it is incumbent on us as professionals to engage in discussions about our view of the kind of citizen we want in our society: one who complies, or one who is a thinker who engages in critical reflection.

The developmental continuum has come to be seen as encapsulating the "professional knowledge" of early childhood educators. However, in this positivist stance, there is little opportunity for the kind of meaning making that Moss (2010) conjures with his interrogation of professionalism. It is possible that after many years of being told what the root skills are, what indicators they should be seeing, and how they should interact, educators may lose confidence in their own sensibilities, interpretations, and responses.

The practice of pedagogical documentation is being embraced by the Ontario Ministry of Education's new pedagogy document for early years, How Does Learning Happen? (Ontario Ministry of Education, 2014) as well as by the Literacy and Numeracy Secretariat (2012), whose focus is on elementary school curriculum. This practice situates the educator alongside the child, with curiosity, documenting how the child investigates the world and makes meaning while the educator also makes meaning. The documentation is intended to be shared with children, colleagues, parents, and the community, recognizing that our knowledge is partial, and inviting other perspectives. Perhaps this is a move "beyond professionalism." Giving visibility to life in the classroom where educators and children are learning together may contribute to increased awareness of the professional work that is done by the educators. How Does Learning Happen? does not include a continuum of development, although the ELECT document is still available as a resource on the Ministry website.

The longstanding practice of creating clinical, objective observations of children may not fit comfortably with the view of the child and educator in the new document, and educators may feel adrift during this time of transition. However, continuing to use the continuum to list skills without addressing the different view of the child on which the practice of pedagogical documentation is based may contribute to confusion. It may take time to internalize the view of the child, family, and educator that is articulated in the new document. However, a view that expresses confidence in professional knowledge, judgment, and reflective practice (sustained by a more expansive view of educators and the system in which they function) can transform early learning.

For professionals, Foucault's (1983) notion of a stance of interrogating dominant discourse is instructive. As he puts it:

Maybe the target nowadays is not to discover what we are, but to refuse what we are. We have to imagine and to build up what we could be to get rid of a 'political double bind,' which is the simultaneous individualisation

\section{Canadian Children}


and totalisation of modern power structures. The conclusion would be that the political, ethical, social, philosophical problem of our days is not to try to liberate the individual from the state, and from the state's institutions, but to liberate us both from the state and from the type of individualisation that is linked to the state. We have to promote new forms of subjectivity through refusal of this kind of individuality which has been imposed upon us. (p. 216)

As a professional community, we can accept this responsibility to engage in challenging conversations about how we are seen, how we see ourselves, and how we see children, to identify messaging about professionalism with which documents and policies are imbued, and, because it is important as part of a critical transformative orientation, to engage in the regular critique of documents that "rule" our lives (Smith, 1987).

\section{Toward Competent ECE Systems}

It is difficult to imagine a notion of competent early childhood educators functioning independently of a system that works to support them. A notion of the competent early childhood educator can become narrow, and consideration must be given to the systemic supports required (and also to potential barriers), otherwise, professionalism is at risk of being reduced to demonstration of a set of measurable and quantifiable competencies (Urban, Vandenbroeck, Van Laere, Lazzari, \& Peeters, 2011, p. 21).

In some ways mirroring our own Ontario conversations, international pockets of conversations are underway about how an articulated notion of competence can contribute to an understanding of professionalism (see Fenech, Sumsion, \& Sheppard, 2010). What lessons can be learned from international practices and investigations? How can what we are learning in Ontario contribute to these conversations? While a review of individual international studies is beyond the scope of this paper, we would like to report on a sensibility of competent systems articulated in one recent 15-country European study (Urban, Vandenbroeck, Van Laere, Lazzari, \& Peeters, 2011, 2012) that we think can contribute to more complex understandings of professionalism.

Economically and politically, Europe faces a number of challenges at the moment - poverty, access to jobs, political upheaval. Socially, Europe has enshrined the United Nations Convention on the Rights of the Child in its Charter of Fundamental Rights of the European Union (Jones \& Walker, 2011), seeing children's access to highquality, affordable child care as a right. Early childhood education and care is seen as potentially contributing to mitigating economic, social, and political problems.

In a joint study (Urban et al., 2011) conducted by the University of East London and the University of Ghent and reported on by Urban et al. (2012), an international 
exploration of what constitutes competent systems in ECEC was conducted to identify the systematic supports that would be necessary to develop, maintain, and sustain ECEC contexts and support early childhood educators who are educated, highly qualified, and competent. The report identifies that while unique approaches are being adopted by different European countries, they share a commitment to considering change at four levels: individual; institutional and team; interinstitutional; and governance. The approaches are grounded in a commitment to understand professionalism in holistic and systemic ways, such as "the German concept of Bildung, the Danish concept of social pedagogy and the Italian concept of collegialità" (2012, p. 32). They also share a commitment to seeing the competent early childhood professional within an intentional and purposeful context of the competent system.

A 'competent system' requires possibilities for all staff to engage in joint learning and critical reflection. This includes sufficient paid time for these activities. A competent system includes collaborations between individuals and teams, institutions (pre-schools, schools, support services for children and families...) as well as 'competent' governance at policy level. (2012, p. 21, emphasis in original)

Working toward a competent system requires an intentional, purposeful reciprocity. It requires a focus on examining the systemic issues or barriers, such as wage parity, that prevent the kind of collaboration among different levels of interaction; simultaneously it requires finding ways to build intentional relationships.

Competent systems in early childhood do not emerge out of aspiration alone. If competence is to unfold in reciprocal relationships between actors at all levels of a system, certain conditions must be in place across the entire system. Brought together in a coherent framework, they render early childhood education and care ... a deeply democratic practice at the core of society. (Urban et al., 2012, pp. 516-518)

Assuming this holistic perspective, the notion of professionalism as competence moves beyond individual competencies identified and identifiable through measurable "knowledge, skills, and attitudes" (Urban et al., 2011, p. 33) to more expansive considerations of "knowledge, practices, and values" (p. 33). This is a shift from the question "do I do things right?" to "do I do the right things?" (p. 33), a shift that embraces more readily the concerns that Moss (2010) provokes in his invitation to move beyond narrow understandings of professionalism. Furthermore, the report concludes that "by referring to values instead of attitudes we intend to distance ourselves from an 'individualised' conceptualisation of ECEC purposes to move toward a vision of early childhood education that underpins negotiated goals and collective aspirations" (Urban et al., 2011, p. 33, emphasis in original). 


\section{Toward a Locally Grown Ontarian Competent ECEC System}

It is early to say how change will unfold in the Ontario early childhood context. It is also not advisable to import, without critical consideration, international solutions to local contexts. Recognizably, in a rapidly global world, policy and knowledge transfer is an increasing reality (Dolowitz \& Marsh, 2000; Steiner-Khamsi, 2006), although taking ideas that work elsewhere without thoughtful consideration to how they can grow in a grassroots local context is not only impulsive, but also prone to failure. Taking up the notion of a competent system requires a focus that is complex and multipronged. It requires that attention be focused to unfold across individual, team or institutional, interinstitutional, and governance levels.

Across these different levels of a competent system, the challenge now is to communicate optimism that early childhood educators are most certainly capable of noticing, documenting, and sharing with others their interpretation of children's meaning making, and of critically reflecting on the meaning of the messages in the learning environment independent of a checklist. The long-held ideal of objectivity in preparing clinical observations of children is giving way to rigour in pedagogical documentation, foregrounding relationship and recognizing subjectivities. There is transparency in this work, and accountability by the nature of its inclusion of documented data and its invitation to share other perspectives. This change in view of the role of the early childhood educator may be liberating.

The Ontario College of Early Childhood Educators (CECE) was formed five years ago. The creation of the CECE was seen as a significant move toward recognition of early childhood education as a profession, and was promoted in this way by the Association of Early Childhood Educators, Ontario, who lobbied for several years for the establishment of the College (College of Early Childhood Educators, 2014). Because it is a professional self-regulatory body, a role of the College is to make the ECE profession self-governing. It protects the public by regulating who can be licensed as a professional early childhood educator and by providing an avenue for complaints about practice if a member is alleged to have failed to abide by the code of ethics and standards of practice (College of Early Childhood Educators, n.d.). As a body accountable for defining professionalism and ensuring ongoing professional development, the CECE is entrusted with great responsibility and has the capacity for great responsiveness. It is introducing a new Continuous Professional Learning initiative this year, and the fact that the framework does not prescribe a set number of hours of learning suggests an approach that is not based on compliance with a quantifiable indicator.

Community colleges and universities with educator preparation programs can also work to encourage critical reflection in students/graduates. Also, through their numerous connections with the community, colleges and universities with educator preparation programs can provide opportunities to question underlying assumptions about the view of

\section{Canadian Children}


the child and educator implied in policies and practices and in the dominant discourse of developmentalism. They can also provide opportunities to advocate for competent systems that respect the intelligence of children, families, and educators and to see this advocacy as a professional responsibility.

Teachers can, as reflexive practitioners, both contest dominant discursive thinking on children's development and learning, as well as produce and formulate new knowledge about children derived from their experiences from the practices they enact.... In other words, discursive analysis helped us, and still helps us, displace our thinking around pedagogical practices and contest the discursive structures identified. Hence, doing discursive analysis proved to be, and will continue to be, of vast importance in the learning processes of practitioners as well as in teacher training. (Lenz Taguchi, 2010, p. 84)

This perspective of a locally grown competent system will enable critical conversations about the nature of change that hold potential to bring into being a new kind of early childhood professional, as Moss (2010) invites.

\section{References}

Abram, D. (1996). The spell of the sensuous: Perception and language in a more-thanhuman world. New York, NY: Vintage Books.

Affiliated Services for Children and Youth. (2002). Raising the bar. Retrieved from: https://ascy.ca/raising-the-bar/

Best Start Expert Panel on Early Learning. (2007). Early learning for every child today: A framework for Ontario early childhood settings. Retrieved from: http://www.children.gov.on.ca/htdocs/English/topics/earlychildhood/early learnin g_for_every_child_today.aspx

Burman, E. (1994). Deconstructing developmental psychology. London, UK: Routledge.

Cannella, G. (1997). Deconstructing early childhood education: Social justice and revolution. New York, NY: Peter Lang.

College of Early Childhood Educators. (n.d.). Ethical and professional standards for early childhood educators: Promoting excellence in professional practice. Retrieved from: http://www.collegeece.ca/en/Documents/CECE_Brochure_Code_Ethics_Standards_Practice_English _WEB.pdf 
College of Early Childhood Educators. (2014). History of the college. Retrieved from: http://www.college-ece.ca/en/AboutUs/Pages/History-.aspx

Costa, A. L., \& Kallick, B. (1993). Through the lens of a critical friend. Educational Leadership, 51(2), 49-51.

Dahlberg, G., Moss, P., \& Pence, A. (2007). Beyond quality in early childhood education and care: Languages of evaluation. New York, NY: Routledge.

Dolowitz, D. P., \& Marsh, D. (2000). Learning from abroad: The role of policy transfer in contemporary policy-making. Governance: An International Journal of Policy and Administration, 13(1), 5-24.

Edwards, C., Gandini, L., \& Forman, G. (2012). The hundred languages of children: The Reggio Emilia experience in transformation ( $3^{\text {rd }}$ ed.). Santa Barbara, CA: Praeger.

Fenech, M., Sumsion, J., \& Sheppard, W. (2010). Promoting early childhood teacher professionalism in the Australian context: The place of resistance. Contemporary Issues in Early Childhood, 11(1), 89-104.

Foucault, M. (1978). The history of sexuality. Vols I-III. New York, NY: Pantheon.

Foucault, M. (1983). The subject and power. Afterword to H. Dreyfus \& P. Rabinow (Eds.), Michel Foucault: Beyond structuralism and hermeneutics (pp. 208-264), Chicago, IL: Chicago University Press.

Foucault, M. (1988). Politics, philosophy, culture: Interviews and other writings 19771984. London, UK: Routledge.

Fraser, S. (2011). Authentic childhood: Experiencing Reggio Emilia in the classroom (3 ${ }^{\text {rd }}$ ed.). Scarborough, ON: Nelson Thomson Learning.

Freire, P. (1970). Pedagogy of the oppressed. New York, NY: Continuum.

Freire, P. (1974). Education for critical consciousness. New York, NY: Bloomsbury Academic.

Giroux, H. A. (1990). Curriculum theory, textual authority, and the role of teachers as public intellectuals. Journal of Curriculum and Supervision, 5(4), 361-383.

hooks, b. (2010). Teaching critical thinking: Practical wisdom. New York, NY: Routledge.

Jones, P., \& Walker, G. (2011). Children's rights in practice. Los Angeles, CA: SAGE.

Katz, L. (1996). Child development knowledge and teacher preparation: Confronting assumptions. Early Childhood Research Quarterly, 11, 135-146.

Canadian Children 
Labaree, D. F. (1992). Power, knowledge, and the rationalization of teaching: A genealogy of the movement to professionalize teaching. Harvard Educational Review 62(2), 123-154.

Lakoff, G., \& Johnson, M. (2003). Metaphors we live by. Chicago, IL: University of Chicago Press.

Lenz Taguchi, H. (2010). Going beyond the theory/practice divide in early childhood education: Introducing an intra-active pedagogy. New York, NY: Routledge.

Literacy and Numeracy Secretariat. (2012). Pedagogical documentation: Leading learning in the early years and beyond. Retrieved from: http://www.edu.gov.on.ca/eng/literacynumeracy/inspire/research/CBS_Pedagogic al.pdf

MacNaughton, G. (2003). Shaping early childhood: Learners, curriculum, and contexts. Berkshire, UK: Open University Press.

MacNaughton, G. (2005). Doing Foucault in early childhood studies: Applying poststructural ideas. London, UK: Routledge.

Malaguzzi, L. (1993). For an education based on relationship. Young Children, 49(1), 912.

Malaguzzi, L. (1994). Your image of the child: Where teaching begins. Exchange, 3, 1-5.

McLuhan, M. (1994). Understanding media: The extensions of man (30 ${ }^{\text {th }}$ anniversary edition). Cambridge, MA: MIT Press.

Moss, P. (2010). We cannot continue as we are: The educator in an education for survival. Contemporary Issues in Early Childhood, 11(1), 8-19.

Ontario Ministry of Education (2014). How does learning happen? Retrieved from: http://www.edu.gov.on.ca/childcare/HowLearningHappens.pdf

Osgood, J. (2006). Deconstructing professionalism in early childhood education: Resisting the regulatory gaze. Contemporary Issues in Early Childhood, 7(1), 514.

Pelo, A. (2008). Rethinking early childhood education. Milwaukee, WI: Rethinking Schools.

Penn, H. (2009). Understanding early childhood: Issues and controversies. New York, NY: Open University Press. 
Rinaldi, C. (2006). In dialogue with Reggio Emilia: Listening, researching, and learning. New York, NY: Routledge.

Smith, D. (1987). The everyday world as problematic: A feminist sociology. Boston, MA: Northeastern University Press.

Steiner-Khamsi, G. (2006). The economics of policy borrowing and lending: A study of late adopters. Oxford Review of Education, 32(5), 665-678.

United Nations. (1989). Convention on the rights of the child. Retrieved from: http://www.ohchr.org/en/professionalinterest/pages/crc.aspx

Urban, M., Vandenbroeck, M., Van Laere, K., Lazzari, A., \& Peeters, J. (2011). Competence requirements in early childhood education and care: Research documents. London, UK: European Commission, Directorate General for Education and Culture.

Urban, M., Vandenbroeck, M., Van Laere, K., Lazzari, A., \& Peeters, J. (2012). Toward competent systems in early childhood education and care: Implications for policy and practice. European Journal of Education, 47(4), 508-526.

Winder, C., \& Corter, C. (2014). Working with families and the wisdom of experience. Interaction, 28(1), 11-18. 


\section{In this issue:}

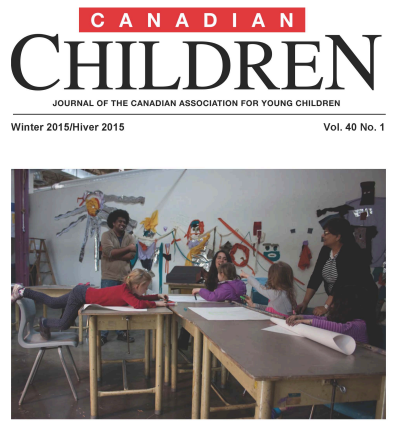

From the Editors' Desk Special Issue: Professionalism in ECEC Guest Editors: Dr. Rachel Langford, Dr. Jane Hewes, Sonya Hooper, and Monica Lysack

Beyond Professionalism: Interrogating the Idea and the Ideals by Randa Khattar and Karyn Callaghan

Negotiating Status: The Impact of Union Contracts on the Professional Role of RECEs in Ontario's Full-Day Kindergarten Program by Romona Gananatham

The Glass Ceiling Effect: Mediating Influences on Early Years Educators' Sense of Professionalism by Stefanie Tukonic and Debra Harwood

Enhancing Professionalism and Quality Through Director Training and Collegial Mentoring by Glory Ressler, Gillian Doherty, Tammy McCormick Ferguson, and Jonathan Lomotey

Authoring Professional Identities: Immigrant and Refugee Women's Experiences in an Early Childhood Teacher Education Program by Christine Massing

ECEs as Childcare Advocates: Examining the Scope of Childcare Advocacy Carried out by ECEs from the Perspective of Childcare Movement Actors in Ontario and Manitoba by Lyndsay Macdonald, Brooke Richardson, and Rachel Langford

From Child-Minders to Professionals: Insights From an Action Research Project on Prince Edward Island by Anna Baldacchino, Ray Doiron, Martha Gabriel, Alaina Roach O'Keefe, and Jessica McKenna

Pedagogical Narrations and Leadership in Early Childhood Education as Thinking in Moments of Not Knowing by Iris Berger

Find other articles from this issue at www.cayc.ca 